Full length article

\title{
Relationship between physical activity practice and metabolic profile of postmenopausal women under treatment with aromatase inhibitors for breast cancer
}

\author{
Thais R.S. de Paulo ${ }^{\mathrm{a}, \mathrm{c}}$, Juliana Viezel ${ }^{\mathrm{a}, \mathrm{b}, *}$, Bruna L. Aro ${ }^{\mathrm{b}}$, Sylvia C. Seidinger ${ }^{\mathrm{b}}$, \\ Ana Carolina A.C. Trindade ${ }^{\mathrm{b}}$, Diego G.D. Christofaro ${ }^{\mathrm{d}}$, Ismael F. Freitas Junior ${ }^{\mathrm{b}}$ \\ a Institute of Bioscience, Department of Physical Education, Sao Paulo State University (UNESP), Rio Claro, SP, Brazil \\ ${ }^{b}$ Center of Studies and Laboratory of Evaluation and Prescription of Motor Activities (CELAPAM), Department of Physical Education, Sao Paulo State \\ University (UNESP), Presidente Prudente, SP, Brazil \\ ${ }^{\mathrm{c}}$ Department of Physical Education, Federal University of Amazonas (UFAM), Parintins, AM, Brazil \\ ${ }^{\mathrm{d}}$ Group of Study in Physical Activity and Health, Sao Paulo State University (UNESP), Presidente Prudente, SP, Brazil
}

\section{A R T I C L E I N F O}

\section{Article history:}

Received 18 December 2016

Received in revised form 6 June 2017

Accepted 4 July 2017

\section{Keywords:}

Breast cancer

Aromatase inhibitors

Postmenopausal women

Physical activity

Metabolic variables

\begin{abstract}
A B S T R A C T
Objective: To analyze the relationship between physical activity practice and metabolic profile of postmenopausal women under treatment with aromatase inhibitors (AIs) for the treatment of breast cancer.

Study design: Cross-sectional study, conducted with 101 postmenopausal women (aged 50-80 years). The sample was divided into two groups; group without cancer ( $\mathrm{GW} ; \mathrm{n}=65$ ) and breast cancer group treated with AIs (GC; $n=36$ ). Physical activity (PA) was evaluated by questionnaire. Correlations between physical activity and metabolic variables were made by Pearson's correlation coefficient and the magnitude of these relationships by linear regression.

Results: In GW, there were observed significant inverse correlations between physical activity and VLDL cholesterol $(\beta=-0.036 ; 95 \% \mathrm{CI}=-0.068 ;-0.004)$; triglycerides $(\beta=-0.036 ; 95 \% \mathrm{CI}=-0.015 ;-0.002)$; glycose $(\beta=-0.029 ; 95 \% \mathrm{CI}=-0.047 ;-0.012)$; and $C$-reactive protein $(\beta=-0.44 ; 95 \% \mathrm{CI}=-0.085$; $-0.003)$. However, for women under treatment of AIs there was no relationship between physical activity and metabolic variables.

Conclusion: The amount of physical activity practice is inversely related to lipid profile, glucose and Creactive protein in women without breast cancer. This relation was not observed in the cancer survivors, suggesting that the use of aromatase inhibitors could influence or low intensity of physical activity.
\end{abstract}

(C) 2017 Elsevier B.V. All rights reserved.

\section{Introduction}

Cancer is a multifactorial disease that can be defined as abnormal and uncontrolled growth of cells of an organism [1,2] making it often invasive and metastatic, and can develop in any part of the body [3]. Breast cancer is the second most common type, accounting for $22 \%$ of women worldwide [4]. It is a common disease in industrialized and in developing countries. Recent studies show that this disease may be responsible for six million

\footnotetext{
* Corresponding author at: Department of Physical Education, Sao Paulo State University, UNESP, Rua Roberto Simonsen, 305, 19060-900, Presidente Prudente, SP, Brazil.

E-mail address: juliana_viezel@hotmail.com (J. Viezel).
}

new cases in developed countries and 9.3 million in developing countries [5].

One of the most important risk factors for developing breast cancer is menopause, which is defined as cessation of menstrual cycle for at least one year [6]. Menopause has a major impact on the woman's body and promotes significant changes. Therefore, occurrence of breast cancer in postmenopausal women may be responsible for changes mainly in body composition, with greater weight gain and body fat, especially the fat trunk [7].

Moreover, the treatment of breast cancer is accomplished through aggressive procedures such as radiation, chemotherapy, immunotherapy and hormonal therapy or even surgical procedures such as mastectomy that can cause major physical, social and emotional changes [8]. Among these procedures, hormone therapy is the standard treatment for early breast cancer stage in women with hormone receptor positive (ER+) and it has been used for over 
two decades. Aromatase inhibitors (AIs), that is one type of hormone therapy, are substances that block aromatase enzyme responsible for converting androgens to estrogens in postmenopausal women. Thus, the pathway that transforms testosterone into estradiol, androstenedione into progesterone and modifies androstenedione $(16 \mathrm{OH})$ into estradiol are blocked [9].

Insufficient practice of physical activity has a major health impact and is associated with inadequate health conditions and development of several chronic diseases, especially metabolic syndrome, breast and colon cancer, and heart disease. This condition represents a significant public health problem $[10,11]$. According to scientific studies, physical activity has been recognize as an important strategy to assist in the physical and psychological rehabilitation of the patient [12].

Although the importance of physical activity practice to reverse the side effects of treatment for breast cancer, few studies in the literature correlate the physical activity practice with metabolic variables in women using aromatase inhibitors to treat breast cancer. Thus, the objective of this study is to analyze the relationship between the practice of physical activity and metabolic variables of postmenopausal women under treatment with aromatase inhibitors for the treatment of breast cancer.

\section{Materials and methods}

Sample

This is a cross-sectional study conducted from March 2015 to July 2015 in a city of southeastern Brazil. Women without breast cancer were invited through media (television and newspaper) and breast cancer survivors were recruited through a list of 348 patients provided by the clinical pharmacology department of oncology from the Public Regional Hospital in the city of Presidente Prudente, São Paulo state.

The inclusion criteria of the study for all women were: (i) age between 50 and 80 years; (ii) be postmenopausal (not have had a menstrual cycle for at least one year reported by the subjects) [13]; (iii) not be engaged on regular exercise for at least six months prior to evaluation; (iv) be free of muscle skeletal injuries; (v) be physically able to participate in physical training certificate by the medical doctor; (vi) have signed the consent form and formal clarification to participate in the research. Especially for breast cancer survivors, plus all the criteria mentioned above: use aromatase inhibitors and be in the stages I-III breast cancer. According to this, the study sample consisted of 101 postmenopausal women, being 65 without cancer and 36 cancer survivors treated with aromatase inhibitors.

The study was approved by the Research Ethics Committee of the Sao Paulo State University (number 6727715.1.0000.5402/ 2015).

\section{Data collection}

\section{Anthropometry}

Body mass was measured using a mechanical scale (Filizola) with a precision of $0.1 \mathrm{~kg}$ and a maximum capacity of $180 \mathrm{~kg}$. Height was measured using a fixed stadiometer (Sanny), with precision of $0.1 \mathrm{~cm}$ and length of $2.20 \mathrm{~m}$, according to the methodology proposed by Freitas Jr. et al. [17]. The values of weight and height were used to calculate body mass index (BMI).

\section{Metabolic profile}

Blood samples were collected and analyzed in a specialized laboratory, with $12 \mathrm{~h}$ of fasting for all variables. The collection was carried out in vacuum tube with gel separator without anticoagulant; after collection, the blood was centrifuged for $10 \mathrm{~min}$ at $3000 \mathrm{rpm}$ to separate the serum from other components of the blood, and the serum was used for analysis.

For measurement of glucose was used a colorimetric enzymatic kit processed in a Autohumalyzer unit [14]. Abnormalities of glucose values were defined according to the reference value proposed by the American Diabetes Association [15].

It was evaluated the serum levels of triacylglycerol, total cholesterol, HDL-cholesterol and LDL-cholesterol by an automatic biochemical analyzer RAXT (Technicon, USA) C-reactive protein was measured using an enzymatic kit Elisa: Iimmulite 2000 analyzer (Siemens Healthcare Diagnostics) [16].

\section{Physical activity}

The Baecke Physical Activity Questionnaire was used to assess physical activity. This questionnaire assess physical activity in three different domains (physical activity at work, physical activity in leisure time and occupational physical activity). After the summation of the physical activities of these three areas, a dimensionless score that determines the practice of general physical activity was generated. This instrument has been validated for the Brazilian population by Florindo et al. [18]. This questionnaire has been also tested against the gold standard for physical activity evaluation (doubly labeled water) by Philippaerts et al. [19].

\section{Statistics analysis}

For statistical analysis, we performed the Kolmogorov-Smirnov normality test, which found that the sample had normal distribution, being expressed as mean and standard deviation. The sample characterization analysis was performed using the Student's $t$-test to display the variables stratified by women with and without the disease. The Pearson correlation coefficient was used to investigate the relationship between physical activity practice and metabolic variables. To verify the magnitude of these associations, linear regression (considering the total sample and also stratifying in women without cancer and women with cancer) was used in the unadjusted and adjusted (age, education level, marital status, type of job and time of menopause) models. All analysis were performed using a SPSS statistical software (version 15.0 ) with the level of significance set at $5 \%$.

\section{Results}

The general characteristics of sample indicate that $25 \%$ of GC had high school while none of the women without cancer had done undergraduate degree $(p=0.020)$. There was no statistical difference in marital status, type of work and time of menopause between the groups.

In relation to age, weight, height, BMI and physical activity level, significant differences were not observed among women of both groups (Table 1 ).

Table 2 shows the relationship between physical activity practice and metabolic variables in total sample size and according to the groups. It is observed that higher amount of physical activity is inversely related to glucose in total sample size and VLDL, triglycerides, glycose and C-reactive protein in women of GW. However, this association was not observed in women of GC.

To check the magnitude of the relationship between physical activity practice and metabolic variables, a linear regression unadjusted and adjusted (age, education level, marital status, type of job and time of menopause) was performed. In unadjusted analysis, it was observed that higher physical activity practice was related to lower values of glucose in the total sample size and 
Table 1

Characterization of the sample.

\begin{tabular}{lllll}
\hline & \multicolumn{2}{l}{$\mathrm{GW}$} & & $\mathrm{GC}$ \\
\cline { 2 - 2 } Variables & Mean (SD) & & Mean (SD) & $\mathrm{p}$ \\
\hline Age (years) & $62.19(7.56)$ & & $64.93(8.57)$ & 0.101 \\
Weight $(\mathrm{kg})$ & $72.46(13.59)$ & & $71.13(12.06)$ & 0.627 \\
Height $(\mathrm{cm})$ & $155.51(7.22)$ & & $153.68(5.70)$ & 0.192 \\
BMI $\left(\mathrm{kg} / \mathrm{m}^{2}\right)$ & $29.92(5.14)$ & & $30.28(5.86)$ & 0.749 \\
Physical activity & $6.41(1.66)$ & & $6.51(1.31)$ & 0.748 \\
LDL $(\mathrm{mg} / \mathrm{dL})$ & $133.34(35.45)$ & & $130.22(43.56)$ & 0.708 \\
HDL $(\mathrm{mg} / \mathrm{dL})$ & $50.24(11.00)$ & & $53.60(10.26)$ & 0.152 \\
VLDL $(\mathrm{mg} / \mathrm{dL})$ & $28.36(13.45)$ & & $28.78(11.56)$ & 0.881 \\
Triglycerides $(\mathrm{mg} / \mathrm{dL})$ & $142.48(67.28)$ & & $143.91(57.81)$ & 0.918 \\
Glycose (mg/dL) & $104.18(23.46)$ & & $108.74(24.36)$ & 0.378 \\
C-reactive protein $(\mathrm{mg} / \mathrm{L})$ & $6.90(10.47)$ & & $6.76(6.56)$ & 0.947 \\
\hline
\end{tabular}

GW: group without cancer, GC: breast cancer group, BMI: body mass index, LDL: low-density lipoprotein, HDL: high-density lipoprotein, VLDL: very low-density lipoprotein, SD: standard deviation.

Table 2

Correlation between physical activity and metabolic parameters in women with and without breast cancer.

\begin{tabular}{lll}
\hline & $\mathrm{R}$ & $\mathrm{P}$ \\
\hline Total sample size & & \\
LDL (mg/dL) & -0.079 & 0.445 \\
HDL (mg/dL) & 0.154 & 0.134 \\
VLDL (mg/dL) & -0.132 & 0.201 \\
Triglycerides (mg/dL) & -0.169 & 0.099 \\
Glycose (mg/dL) & $-\mathbf{0 . 2 4 9}$ & $\mathbf{0 . 0 1 4}$ \\
C-reactive protein (mg/L) & -0.142 & 0.173 \\
& & \\
GW & & \\
LDL (mg/dL) & -0.119 & 0.350 \\
HDL (mg/dL) & 0.117 & 0.356 \\
VLDL (mg/dL) & $-\mathbf{0 . 2 5 9}$ & $\mathbf{0 . 0 3 9}$ \\
Triglycerides (mg/dL) & $-\mathbf{0 . 3 1 9}$ & $\mathbf{0 . 0 1 0}$ \\
Glycose (mg/dL) & $-\mathbf{0 . 3 2 6}$ & $\mathbf{0 . 0 0 9}$ \\
C-reactive protein (mg/L) & $-\mathbf{0 . 2 6 2}$ & $\mathbf{0 . 0 3 8}$ \\
GC & & \\
LDL (mg/dL) & & \\
HDL (mg/dL) & 0.086 & 0.640 \\
VLDL (mg/dL) & 0.131 & 0.474 \\
Triglycerides (mg/dL) & 0.239 & 0.188 \\
Glycose (mg/dL) & 0.239 & 0.188 \\
C-reactive protein (mg/L) & -0.080 & 0.655 \\
\hline & 0.354 & 0.051 \\
\hline
\end{tabular}

GW: group without cancer, GC: breast cancer group, LDL: low-density lipoprotein, HDL: high-density lipoprotein, VLDL: very low-density lipoprotein

glucose triglycerides in GW. In the adjusted analysis, this relationship was also observed for VLDL cholesterol and C-reactive protein in the GW. However when analyzing the relationship between physical activity practice and metabolic variables in GC, these relationships were not observed neither in unadjusted nor in the unadjusted analysis (Table 3).

\section{Discussion}

One of the main findings of this study was an inverse relationship between level of physical activity practice and some metabolic parameters in women without cancer. However, findings were not observed in breast cancer survivors using aromatase inhibitors.

Possible absence of the inverse relationship between physical activity level and metabolic variables may be due to the use of AIs. Corroborating this hypothesis, Aydiner et al. [20] in a metaanalysis to identify randomized clinical trials comparing AIs and tamoxifen as primary adjuvant endocrine therapy in postmenopausal women, concluded that the use of AIs provided low risk of thromboembolic events and endometrial cancer, but they also found a higher risk of cardiovascular events. Elisaf et al. [21] examined the effects of AIs on blood parameters in postmenopausal women with breast cancer. After 16 weeks of treatment was observed a significant increase in total cholesterol, LDL and atherogenic risk (total cholesterol/HDL and LDL/HDL), and a decreased HDL. Bell et al. [22] examined the effects of AIs three months before and three months after begin treatment and found that AIs decreased HDL concentrations by approximately $4 \mathrm{mg} / \mathrm{dl}$ and increased approximately $5 \mathrm{mg} / \mathrm{dl}$ of LDL cholesterol.

In several clinical trials that compared the adverse effects of AIs and tamoxifen in breast cancer survivors, a significant increased risk for cardiovascular disease in patients treated with AIs compared with those treated with tamoxifen [23-25]. The cardiac pathology induced by the use of AIs in women under treatment for breast cancer is incipient, although some studies suggest that changing some ways caused by decrease in estradiol circulation can cause consequent changes in lipid metabolism [26].

In contrast, other studies concluded that the use of AIs appear to be associated with fewer serious side effects, showing little to no adverse effects of AIs on cardiovascular health, presenting neutrality in relation to the lipid profile of breast cancer survivors when compared to tamoxifen. However, the authors warn possible adverse changes during the treatment, since the use of AIs are for, at least, five years [27-31] which can alter the metabolic profile during the treatment time.

Varieties of outcomes that address therapy with IA and cardiovascular outcomes that are related to the metabolic variables have been presented in the literature, but there are many differences in the results and how they are reported.

Another hypothesis of our study is about the level of physical activity practiced by women participating in our research. In the present study the relationship between physical activity level and cardiometabolic risk was inversed only in women without breast cancer, and this can be given by the fact that cancer survivors practice less intense physical activity $[32,33]$. Furthermore, AIs can influence the cardiovascular system reducing the possibility of significant findings between physical activity and metabolic profile in breast cancer survivors [34].

Studies in the literature report the need of more moderate to vigorous physical activity intensity to reduce the risk of breast cancer, recurrence, metastasis and cardiovascular events [35-37], and some reductions are even greater with strenuous exercise [38]. However, there are still inconsistencies on the intensity required to reduce these risks, especially in special populations such as the present study.

Although the present study provides new information about the relationship between physical activity practice and metabolic variables in breast cancer survivors under treatment with aromatase inhibitors, some limitations should be pointed out. The sample size was small compared to other studies examining the use of IAs and metabolic variables. The study design limits the reverse causality responses, that is, it is not possible to present the relationship time response. The instrument applied to evaluate physical activity practice is self-reported which may limit clear information on the intensity of the different types of physical activities. Nevertheless, we point out the difficulty of using accelerometer in large samples.

Although the mentioned limitations, our study has strengths that should be highlighted: i) it is one of the few studies that aimed to check whether the physical activity practice could contribute to the reduction of metabolic variables values in postmenopausal breast cancer survivors and compared the results with women without cancer; ii) the metabolic variables were collected through blood analysis, a more accurate method for the evaluation of these parameters when compared to self-reported information from the study participants; iii) despite the assessment of physical activity 
Table 3

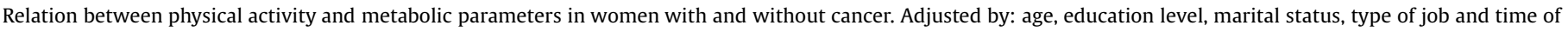
menopause.

\begin{tabular}{|c|c|c|c|c|c|c|}
\hline \multirow[t]{2}{*}{ Physical activity } & \multicolumn{3}{|c|}{ Unadjusted } & \multicolumn{3}{|c|}{ Adjusted } \\
\hline & $\beta$ & CI (95\%) & $\mathrm{p}$ & $\beta$ & $\mathrm{CI}(95 \%)$ & $\mathrm{p}$ \\
\hline \multicolumn{7}{|l|}{ Total sample size } \\
\hline $\mathrm{LDL}(\mathrm{mg} / \mathrm{dL})$ & -0.003 & $-0.012 ; 0.005$ & 0.445 & -0.003 & $-0.012 ; 0.006$ & 0.476 \\
\hline HDL $(\mathrm{mg} / \mathrm{dL})$ & 0.022 & $-0.007 ; 0.052$ & 0.134 & 0.025 & $-0.007 ; 0.056$ & 0.120 \\
\hline VLDL (mg/dL) & -0.016 & $-0.041 ; 0.009$ & 0.201 & -0.018 & $-0.044 ; 0.009$ & 0.191 \\
\hline Triglycerides (mg/dL) & -0.004 & $-0.009 ; 0.001$ & 0.099 & -0.004 & $-0.010 ; 0.001$ & 0.099 \\
\hline Glycose $(\mathrm{mg} / \mathrm{dL})$ & -0.016 & $-0.030 ;-0.003$ & 0.014 & $-\mathbf{0 . 0 2 0}$ & $-0.034 ;-0.006$ & 0.005 \\
\hline C-reactive protein $(\mathrm{mg} / \mathrm{L})$ & -0.024 & $-0.059 ; 0.011$ & 0.173 & -0.027 & $-0.063 ; 0.009$ & 0.140 \\
\hline \multicolumn{7}{|l|}{ GW } \\
\hline $\mathrm{LDL}(\mathrm{mg} / \mathrm{dL})$ & -0.008 & $-0.019 ; 0.004$ & 0.202 & -0.010 & $-0.020 ; 0.001$ & 0.079 \\
\hline HDL (mg/dL) & 0.022 & $-0.016 ; 0.060$ & 0.243 & 0.022 & $-0.020 ; 0.065$ & 0.295 \\
\hline $\operatorname{VLDL}(\mathrm{mg} / \mathrm{dL})$ & -0.030 & $-0.060 ; 0.001$ & 0.054 & -0.036 & $-0.068 ;-0.004$ & 0.027 \\
\hline Triglycerides (mg/dL) & -0.007 & $-0.013 ;-0.001$ & 0.019 & -0.008 & $-0.015 ;-0.002$ & 0.009 \\
\hline Glycose (mg/dL) & -0.027 & $-0.044 ;-0.010$ & 0.002 & -0.029 & $-0.047 ;-0.012$ & 0.001 \\
\hline C-reactive protein $(\mathrm{mg} / \mathrm{L})$ & -0.040 & $-0.079 ; 0.000$ & 0.051 & -0.44 & $-0.085 ;-0.003$ & 0.036 \\
\hline \multicolumn{7}{|l|}{ GC } \\
\hline LDL (mg/dL) & 0.003 & $-0.009 ; 0.015$ & 0.639 & -0.005 & $-0.011 ; 0.020$ & 0.555 \\
\hline $\mathrm{HDL}(\mathrm{mg} / \mathrm{dL})$ & 0.021 & $-0.029 ; 0.071$ & 0.401 & 0.039 & $-0.020 ; 0.088$ & 0.188 \\
\hline VLDL (mg/dL) & 0.021 & $-0.023 ; 0.065$ & 0.328 & -0.019 & $-0.057 ; 0.094$ & 0.511 \\
\hline Triglycerides (mg/dL) & 0.004 & $-0.004 ; 0.013$ & 0.326 & -0.004 & $-0.011 ; 0.019$ & 0.611 \\
\hline Glycose (mg/dL) & 0.002 & $-0.019 ; 0.024$ & 0.823 & 0.002 & $-0.026 ; 0,031$ & 0,874 \\
\hline $\mathrm{C}$-reactive protein $(\mathrm{mg} / \mathrm{L})$ & 0.061 & $-0.015 ; 0.138$ & 0.112 & 0.089 & $-0.002 ; 0.181$ & 0.055 \\
\hline
\end{tabular}

GW: group without cancer, GC: breast cancer group, LDL: low-density lipoprotein, HDL: high-density lipoprotein, VLDL: very low-density lipoprotein.

level be conducted through the questionnaire, there was concern in using an validated instrument for the population and tested against the gold standard method for physical activity (doubly labeled water).

Based on the findings of this study we demonstrated that physical activity level was inversely related with some variables of the metabolic profile in women without breast cancer. The same relationship did not occur in breast cancer women in treatment with AIs. Therefore, it is necessary future studies that address interventions to evaluate the effectiveness of exercise on these markers, since the treatment for breast cancer with aromatase inhibitors for postmenopausal women is considered the gold standard. It has good results for the risk of recurrence and metastasis, but its side effects generally cause impacts on other health parameters of these women. Furthermore, steps should be taken in order to encourage breast cancer survivors to increase their physical activity level.

\section{Competing interest}

All authors declare that they have no potential conflict of interest concerning this article.

\section{Acknowledgement}

This study was supported by Research Support Foundation of Amazonas State (FAPEAM).

\section{References}

[1] Battaglini C, Bottaro M, Dennehy C, Barfoot D, Shields E, Kirk D, et al. The effects of resistance training on muscular strength and fatigue levels in patients with breast cancer. Braz J Sports Med 2006(May/June (2:3)).

[2] Moraes A, Battaglini C, Schmidt LF, Rafael AD, Roussenq SC, Dias M, et al. Strength training and breast cancer: a systematic review. São Paulo. Braz J Exercise Prescription Physiol 2014;8(49):664-73.

[3] American Cancer Society. Cancer facts e Figs. Atlanta: American Cancer Society; 2011. p. 2011.

[4] Jemal A, Siegel R, Xu J, Ward E. Cancer statistics. Cancer J Clin 2010;2010:1-24.
[5] Freire MEM, Sawada NO, França ISX, Costa SFG, Oliveira CDB. Health-related quality of life among patients with advanced cancer: an integrative review. J School Nurs-USP 2014;48(2):357-67.

[6] Whitcroft S, Herriot A. Insulin resistance and management of the menopause: a clinical hypothesis in practice. Menopause Int 2011;17(1):24-8.

[7] Donato GB, Fuchs SC, Oppermann K, Bastos C, Spritzer PM. Association between menopause status and central adiposity measured at different cutoffs of waist circumference and waist-to-hip ratio. Menopause 2006;13(2):280-5.

[8] Lahoz MA, Nysse SM, Correia GN, Garcia APU, Driusso P. Functional capacity and quality of life in women post-mastectomized. São Carlos Braz J Cardiol 2010;56(4):423-30.

[9] Gao O, Patani N, Dunbier AK, Ghazoui Z, Zvelebil M, Martin LA, et al. Effect of aromatase inhibition on functional gene modules in estrogen receptorpositive breast cancer and their relationship with antiproliferative response. Clin Cancer Res 2014;20(9):2485-94.

[10] Lee IM, Shiroma EJ, Lobelo F, Puska P, Blair SN, Katzmarzyk PT. Effect of physical inactivity on major non-communicable diseases worldwide: an analysis of burden of disease and life expectancy. Lancet 2012;380(9838):219-29.

[11] Lipscombe C, Smith KJ, Gariépy G, Schmitz N. Gender differences in the relationship between anxiety symptoms and physical inactivity in a community-based sample of adults with type 2 diabetes. Can J Diabetes 2014;38(6):444.

[12] Emaus A, Veierod MB, Tretli S, Finstad SE, Selmer R, Furberg AS, et al. Metabolic profile, physical activity, and mortality in breast cancer patients. Breast Cancer Res Treat 2010;121:651-60.

[13] De La Salud Organización Mundial. Investigaciones sobre la menopausia en los años noventa. Genebra: Organización Mundial de la Salud; 1996.

[14] Human RP, Jones GA. Evaluation of swab transport systems against a published standard. J Clin Pathol 2004;57:762-3.

[15] Expert committee on the diagnosis and classification of diabetes mellitus: report of the expert committee on the diagnosis and classification of diabetes mellitus. Diabetes Care 1997;20:1183-97.

[16] Friedenreich CM, Neilson HK, Woolcott CG, Wang O Stanczyk FZ, McTiernan A, et al. Inflammatory marker changes in a yearlong randomized exercise intervention trial among postmenopausal women. Cancer Prev Res 20125 (January (1)).

[17] Freitas Jr IF, et al. Padronização de Técnicas Antropométricas. Ed Cultura Acadêmica (Presidente Prudente, SP). 2009.

[18] Florindo AA, Latorre Mdo R, Jaime PC, Tanaka T, Zerbini CA. Methodology to evaluation the habitual physical activity in men aged 50 years or more. Rev Saude Publica 2004;38(2):307-14.

[19] Philippaerts RM, Westerterp KR, Lefevre J. Doubly labelled water validation of three physical activity questionnaires. Int J Sports Med 1999;20(5):284-9.

[20] Aydiner Adnan. Meta-analysis of breast cancer outcome and toxicity in adjuvant trials of aromatase inhibitors in postmenopausal women. Breast 2013;22:121-9.

[21] Elisaf MS, Bairaktari ET, Nicolaides C, Kakaidi B, Tzallas CS, Katsaraki A, et al. Effect of letrozole on the lipid profile in postmenopausal women with breast cancer. Eur J Cancer 2001;37(12):1510-3. 
[22] Bell LN, Nguyen ATP, Li L, Desta Z, Henry NL, Daniel Hayes FDF, et al. Comparison of changes in the lipid profile of postmenopausal women with early stage breast cancer treated with exemestane or letrozole. J Clin Pharmacol 201252(12).

[23] Amir E, Seruga B, Niraula S, Carlsson L, Ocana A. Toxicity of adjuvant endocrine therapy in postmenopausal breast cancer patients: a systematic review and meta-analysis. J Natl Cancer Inst 2011;103:1299-309.

[24] Cuppone F, Bria E, Verma S, Pritchard KI, Gandhi S, Carlini P, et al. Do adjuvant aromatase inhibitors increase the cardiovascular risk in postmenopausal women with early breast cancer: meta analysis of randomized trials. Cancer 2008;112:260-7.

[25] Seruga B, Zadnikb V, Grasic Kuhara C, Marinkoc T, Cuferd T, Zakotnika B, et al Association of aromatase inhibitors with coronary heart disease in women with early breast cancer. Cancer Invest 2014;32(4):99-104.

[26] Pritchard KI, Abramson BL. Cardiovascular health and aromatase inhibitors. Drugs 2006;66(13):1727-40.

[27] Gallicchio L, Calhoun C, Helzlsouer K. Effect of aromatase inhibitor therapy on the cardiovascular health of black and white breast cancer patients. Clin Breast Cancer 2016;16(3):23-31.

[28] Geisler J, Lonning PE. Aromatase inhibitors as adjuvant treatment of breast câncer. Crit Rev Oncol Hematol 2006;57:53-61.

[29] Markopoulos C, Polychronis A, Dafni U, Koukouras D, Zobolas V, Tzorakoleftherakis $E$, et al. Lipid changes in breast cancer patients on exemestane treatment: final results of the TEAM Greek substudy. Ann Oncol 2008;1-7.

[30] Ligibel JA, James OA, Fisher M, Daniel GW, Winer EP, Keating NL. Risk of myocardial infarction, stroke, and fracture in a cohort of community-based breast cancer patients. Breast Cancer Res Treat 2012;131:589-97.
[31] Van Polnark C, Makris A, Clack G, Barlow DH, Eastell R. Lipid profiles within the sabre trial of anastrozole with and without risedronate. Breast Cancer Res Treat 2012;134(3):1141-7.

[32] Irwin ML, Crumley D, McTiernan A, Bernstein L, Baumgartner R, Gilliland FD, et al. Physical activity levels before and after a diagnosis of breast carcinoma. Cancer 2003;97:1746-57.

[33] Irwin ML, McTiernan A, Bernstein L, Gilliland FD, Baumgartner R, Baumgartner $\mathrm{K}$, et al. Physical activity levels among breast cancer survivors. Med Sci Sports Exercise 2004;36:1484-91.

[34] Coates AS, Keshaviah A, Thurlimann B, Mouridsen H, Mauriac L, Forbes JF, et al. Five years of letrozole compared with tamoxifen as initial adjuvant therapy for postmenopausal women with endocrine-responsive early breast cancer: update of study BIG 1-98. J Clin Oncol 2007;25:486-92.

[35] Tehard B, Friedenreich CM, Oppert JM, Clavel-Chapelon F. Effect of physical activity on women at increased risk of breast cancer: results from the E3N Cohort Study. Cancer Epidemiol Biomarkers Prev 2006;15:57-64.

[36] Dallal CM, Sullivan-Halley J, Ross RK, Wang Y, Deapen D, Horn-Ross PL. Longterm recreational physical activity and risk of invasive and in situ breast cancer. Arch Intern Med 2007;167:408-15.

[37] Friedenreich CM, Cust AE. Physical activity and breast cancer risk: impact of timing, type and dose of activity and population subgroup effects. Br J Sports Med 2008;42:636-47.

[38] Howard Regan A, Leitzmann Michael F, Linet Martha S, Michal Freedman D. Physical activity and breast cancer risk among pre- and postmenopausal women in the U.S. radiologic technologists cohort. Cancer Causes Control 2009;20(April (3)):323-33. 